\title{
Best scientific advice is to read the climate report
}

\section{Most researchers agree on the need to back Kyoto: let politicians deal with the politics.}

Sir - Your Editorial "Not just academic" (Nature 431, 1; 2004) on the political climate in Russia stresses the importance of respecting academic freedom. But this is beside the point. To avoid bowing to political pressure, or indeed political incentives, Russian scientists should simply stop giving any political advice (either unsolicited or solicited) and confine themselves to developing genuine scientific concepts that reflect reality, not opinions.

Most conscientious researchers can distinguish the ideological and scientific aspects of the problems they study, and keep them separate. The existing range of scientifically justified concepts on climate change provides a wide, but well delineated, field for political manoeuvring. There is a broad consensus among climate scientists that humankind must urgently develop legal, institutional and financial mechanisms for regulating climate. The extent of regulation that's needed is open to debate, but most scientists support the Kyoto Protocol as the first practical step towards this goal.
However, the problem of assessing the costs of such actions is traditionally tackled by politicians, not scientists. If we all agree that such problems are best addressed through politics, it is clear that the only advice a conscientious researcher can give to a Russian politician is as follows: "Read the reports of the Intergovernmental Panel on Climate Change."

\section{Georgii Alexandrov}

Institute of Atmospheric Physics,

Russian Academy of Sciences,

Pyzhevsky per. 3, Moscow 109017, Russia

\section{Climate: Russians face another disappointment}

Sir - In the News Feature "Crunch time for Kyoto" (Nature 431, 12-13; 2004) you mention the lack of public pressure on Russian president Vladimir Putin to begin tackling climate change and ratify the Kyoto treaty. There seems to be a widespread belief in Russia that climate change is a peripheral issue, unrelated to the supply of jobs, to putting a roof over your family's head or food on your table. Add to this the belief that a warmer climate would be an improvement — taking some of the chill out of winter and maybe increasing harvests - and it's little wonder that climate change isn't on the lips of every Russian voter.

However, the reality of climate change for Russia, and boreal Asia as a whole, is unlikely to be the balmy-weathered, bumper-harvest future some expect. Although increasing temperatures may well allow extended growing seasons and a northward shift in crop zones, increased damage from pests, drought and severe weather could lead to a $30 \%$ cut in cereal production by 2050 across the region, with Siberia seeing a decrease of up to $20 \%$ in agricultural output (see Intergovernmental Panel on Climate Change Climate Change 2001: Impacts, Adaptation and Vulnerability Cambridge University Press, Cambridge, UK; 2001).

Even if the net effect is an increase in food production, it is likely to come at a price. Industries such as mining and construction face soaring costs as a result of melting permafrost, increased flooding and building subsidence. The health and transport sectors could come under huge additional pressure, and international tensions are likely to be inflamed by water shortages, famine and mass migration in other parts of Asia.
For our Russian voter then, living through Russia's already painful social and economic post-Soviet transition, climate change threatens to make life more painful still.

David S. Reay

Institute of Atmospheric and Environmental Science, School of GeoSciences, Darwin Building, University of Edinburgh, Mayfield Road, Edinburgh EH9 3JU, UK

\section{Passion and politics cloud the climate debate}

Sir - I question the view expressed in "Crunch time for Kyoto" (Nature 431, 12-13; 2004) that Russian attitudes towards the Kyoto Protocol are "heavily influenced by its dented pride and need for respect", as a former superpower. I suggest that concerns held by members of the Russian Academy of Sciences about Kyoto, and their surprise at British delegates' complaints about the inclusion of climate-change 'sceptics', are shaped by disquieting memories of the Soviet era.

It is 40 years since the end of Trofim Lysenko's dictatorship over Soviet biology. A poorly educated agronomist, Lysenko gained political support during the agricultural crisis of the 1930s by denouncing conventional genetics as a "bourgeois deception" and promising improved crop yields on the basis of crude and unsubstantiated "experiments". He became the autocrat of Stalinist science, with catastrophic results that linger today.

Lysenkoism was a tragic example of an illusion that became accepted as reality, despite all contrary evidence, because it was continually affirmed at meetings and by the media - see V. N. Soyfer's Lysenko and the Tragedy of Soviet Science (tr. L. \& R. Gruliow, Rutgers University Press, New Brunswick; 1994). In 1965, Academician and Nobel prizewinner Nikolai N. Semyonov was finally able to write: "There is nothing more dangerous than blind passion in science. This is a direct path to unjustified self-confidence, to loss of selfcriticalness, to scientific fanaticism, to false science. Given support from someone in power, it can lead to suppression of true science, and, since science is now a matter of state importance, to inflicting great injury on the country."

Russian distrust of the interaction between science and politics remains strong. To many of the academicians, as to many of their colleagues around the world, the global-warming paradigm is far from 'fact', but objective debate is distorted by political and commercial interests. In this context, I suggest that it was perfectly reasonable for the academy's programme to include scientists with a range of viewpoints. It was unfortunate that the British delegation tried to exclude a selection of these because - as one member is reported as saying (Science 305, 319 ; 2004) — "We knew that we would not get to the scientific issues if we went down every rabbit hole of scepticism."

The "sceptics" who were invited, including myself, were not speaking about the Kyoto Protocol. For my part, I argued against claims that malaria and other mosquito-borne diseases are spreading to new latitudes and altitudes because of climate change.

I feel no offence at being branded a sceptic - quite the contrary — but I never dreamt that I would hear a top Russian administrator at a Kremlin press conference refer to me, a British scientist, as a "dissident", and to the representatives of the British government as "totalitarians" who had tried to "censor" me to protect their Party. Truly, an irony of history.

\section{Paul Reiter}

Pasteur Institute, 25-28 rue du Dr Roux,

Paris 75724, France 